\title{
ÖRGÜT KÜLTÜRÜ: TANIMLAR VE YAKLAŞIMLAR
}

\section{Asłı YAĞMURLU*}

Bildiǧimiz kadanyla ơrgüt kültürü kavramı 1980'lerde önem kazandı. Pettigrew'in Administrative Science Quarterly'de 1979'da yayınlanan "Örgüt Kültürleri Üzerine" (On Studying Organizational Cultures) adlı makalesi bu ivmenin başlangıcı olarak kabul edilebilir. Daha sonra konunun Business Week'in Ekim 1980 sayısı ve Fortune dergisinin Mart 1982 sayısında tarışılmasıyla konu akademik yazın dışında kamuoyunda da popülerlik kazandı. Kültür fikri yeni olmamakla birlikte, örgüt bağlamında kültürün tartuşılması yeniydi. Konu antropologlar, yőnetim bilimciler, örgüt bilimciler, iletişim bilimciler ve sosyal psikologlar tarafından ilgiyle karşılandı.

1960'larla beraber çalışmalar sonuç vermeye başlamışt. ABD'de Harsison Trice liderliğindeki bir grup araştırmacı (Trice, Belasco ve Alutto, 1969) personel davranışlarındaki kültürel ritler ve törenlerle ilgili gözlemlerini yayınlamışlardı. Ingiltere'de Barry Turner "Endüstriyel Alt Kültürün Keşfi" (Expoiring the Industrial Subculture) kitabını yazmış ve ơrgüt kültürünün yapısı ve varlığına odaklanarak, incelemeler yapmıştir.

Birkạ̧ yıl sonra Ingiliz sosyolog Pettigrew önceden de belirttiğimiz, "Örgüt Kültürleri Üzerine" adlı adından çok sơz ettiren makalesini Administrative Science Quarterly'de yayınlamışu. Bu makale ile Pettigrew örgüt kültürü kavramına yönetsel araşurmalar açısından yaklaşmışu;

"Günlük amaç ve konuların peşindeyken daha az araçsal olanlar kolay unutulur, etrafımızdaki bu konulara daha kuvvetli toplumsal doku anlam kazandını. Yine de bireylerin verili bir ortamda işlev görebilmeleri için devamlı olarak üzerinde hareket edebilecckleri gerçeklik duygusuna sahip olmalan gerekir. Kültür belirli bir grup için belli bir zaman diliminde geçerli olan, kabul edilmiş anlamlar büttünüdür ve bence kültürün tezahürü sembol, dil ideoloji, inanç, ritüel ve mitlerdir." (1979:574)

Bu dönemde konuyla ilgili iki tane 'best seller' kitap basılmıştır; Peters ve Waterman'ın (1982) "Mükemmellik Arayışı" (In Search of Exellence) ve Ouchi'nin

\footnotetext{
* TODAIE Asistanı
} 
(1981) "Z Teorisi" (Theory Z). Konu onemli üç akademik dergide (The Journal of Management Studies (1982), Administrative Science Quarterly (1983) ve Journal of Management (1985)) makalelerin yanı sıra ozzel sayı olarak da işlenmiştir.

Kültür konusu farklı sebeplerden ilgi odağı olmuştur. Bu ilginin nedeni açık olmamakla birlikte bazı yazarlar (Meek, 1988; Lincoln ve arkadaşları, 1986; Morgan, 1986; Smircich ve Calas, 1987) iki temel neden üzerinde durmuşlardır. Bunların birincisi bat toplumlanndaki sosyoekonomik düzey, ikincisi ise entellektuiel söylem düzeyidir.

1980'lerde batı toplumları ekonomilerinde büyük bir düşüs yaşamışlardı. Dił̌er taraftan bir doğu ülkesi olan Japonya uluslararası pazarlann kontrolünủ ele geçirmeye başlamışı. Tamamiyle başka bir küitiüre sahip Japonlanın dünya ekonomik liderliğinde Amerika Birleşik Devletlerinin rakibi haline gelmesi, o zamana kadar üstünlügüu tartışılmaz kabul edilen Amerikan yönetim anlayışının yetenek ve fikirlerinin sorgulanmasına sebep olmuştur.

Hiç bir doğal kaynă̆ı, enerjisi olmayan, dağlık 4 adada yaşayan, 110 milyon insandan oluşan bu ülkenin ekonomik alandaki başarısı tüm batı dünyasının çok büyük ilgisini çekmiştir. Batılı girişimciler kendilerini sorgulamaya başlamışlar, çeşitli akademisyenler de bu başanının altındaki nedeni tartışırken, çoğunluğu bunun ülkenin kültïr ve gündelik yaşam pratiklerinden kaynaklandığı konusunda fikir birlił̆ine varmıştı. Bu döneme kadar rekabet edilemez olduğu düşünülen Amerikan yönetim anlayışı, 1980'lerdeki gelişmelere arzu edilen cevapları verememiştir. Çözüm onerilerinin başarısızlığı, uygulayıcıları ve akademisyenleri yeni çözüm onerileri aramaya itmiş ve bazı akademisyenler örgütlerde verimliliğin arturılması için cevabın örgüt kültürü çalışmalarında olduğuna inanmışlardır. Konu ile ilgili kaynaklara bakuğımızda Japonların 'mistik' gündelik yaşam pratikleri ve iş anlayışlarının literatüre olan büyük etkisi görülmektedir. Ömeğin Gregory'ye göre; "kültür nosyonu gencllikle egzotik, uzak insan ve ülkelerin, mit, rit, dil ve pratikleri ile ilişkilendirilir" (1983:359). Bu tür düşünüşün arkasında yatan neden, Japon yőnetim tarzının mistik olduğu kanısıdır. Semboller, mitler ve adetlerin anlaşılmasıyla Japon mistik yönetim anlayışının anlaşılacă̆ı bununla da batılı yöneticilerin aynı verimlilik düzeyine erişeceği düşünülmüştür. Amerikalı yőneticiler kültürü, yöneticiler ve çalışanların isteklerini kaynaştıracak ve bőylece örgütte uzlaşma ve işbirlił̌i oluşturacak bir yol olarak görmüşlerdir.

Günümüzde konu üzerindekj tartışmalar son bulmuş ve sőz konusu alanda ơrgüt kültürü yazını kuramsal izlerini kesin olarak bırakmıştır. Örgüt kültürü kavramını açıklamak için başlangıç olarak 'örgüt' ve 'kültür' kavramlarını irdelemenin yerinde olacağı kảnısındayım. 'Kültür' sözciiğünün pek çok anlamı vardır. Diğer bir çok anlamlı sőzcük olan 'örgüt' sözcuigü ile bir arada kullanıldığında hem konu hem de anlam yơnünden akıl kanştıncı olabilir. Her iki kavram üzerinde sıkça konuşulmasına rał̆men tanımlanmaları zordur.

Tanımı zorlaştıran ilk neden ơrgüt kültürünün yeni bir çalışma alanı olmasıdır. Bu, ơrgüılerin araştırılması için deģişik bir düşünüş ve bakıı̧ açısıdır. Hofstede ve arkadaşlarının belirttigi gibi;

"Tanım üzerinde bir görü̧̧ birlił̆i olmamasına rağmen çoğu yazar örgüt kültürünün aşă̆ıdaki nitelikleri konusunda görüşbirliği içindedir; 1. bütüncül 
olması, 2. tarihsel niteliği, 3. antropolojik konularla ilgisi, 4. toplumsal yapısı, 5. esnekliği ve 6. değişiminin zorluğu". (1990:296)

Örgütün yukarıda sıralanan niteliklerinin, örgüt çalışmalarında daha ơnceden de ortaya konduğunu biliyoruz. Ancak bu niteliklerin bir yapı içinde ilk kez bir araya getiren orgüt kültürü çalışmalarıdır. Söz konusu ozelliklerden bazılarının birbiriyle çelişkili gőrünmesinin sebebi kültür kavramının nitelił̌inden kaynaklanmaktadır. Göz ardı edilmemesi gereken bir gerçek de orgüt kültürü yazınında sistematik bir zemin bulunmamasının getirdiği sınırlılıklardır.

Tanım zorluğunun ikinci nedeni ise, konunun kültürel yanından kaynaklanmaktadır. Orgütün kültürel gerçekliği; değerler, inançlar, varsayımlar gibi sınırları belirsiz kavramlardan oluşur. Tüm bunların gözlenmesinin zor olduğ bu bir gerçektir. Orgütün kültürel yanının anlaşllabilmesi için kültürün gözlemlenebilen yanlarından yararlanmak gerekmektedir. Ritler, ritüeiler, törenler, oyküler, semboller ve dil bunların en yaygın olanlandır. Kültürün yorumlanması için gözlemlenebilen yanlann üzerinde durulması gereklidir ancak yine de bir problem ortaya çımaktadır; bir şirketin ơdül töreni ile başka bir şirketinki aynı anlama gelmeyebilmektedir. Örgütte neler olduğunu anlayabilmek için olayiara içeriden bakma zorunluluğu da vardır.

Örgüt külttürünün ne olduğunun daha iyi kavranabilmesi için òncelikle kültürü ve kültür-örgüt arasındaki ilişkiyi açıklamamı gerekir. Konunun anlaşılması için kültür ve orgütün kısa tanımlanyla işe başlayabiliriz. Collins Sosyoloji sőzlügüünde (1991:138), kültür, "insan yaratılan, sembol ve eşyanın kullanımı" olarak tanımlanmaktadır, "kültüir, tüm bir toplumun yaşam tarzını oluşturur ve davranış kodlarını, giyimi, dili, ritüelleri, davranış normlanını ve inanç sistemlerini içerir". Aynı sőzlük ơrgütả (1991:444), "belirli bir amaç için bir araya gelmiş resmi kurallar yapısına, otorite ilişkilerine sahip, işboblümü ve sınırlı üyeliği olan topluluk" olarak tanımlamaktadır. Bu tanım modern toplumun gündclik yaşamında görebileceğimiz karmaşık örgütleri yani, hastaneleri, okullan, úniversiteleri, partileri veya şirketleri kastetmektedir. Aynı sözlükteki ikinci bir tanımda örgüt, "herhangi bir amacı olan sosyal aktivite veya aktiviteler topluluğu" olarak tarif edilmektedir. Bu kısa tanımlardan sonra kültürün örgütsel çözü̈mlemede ne anlama geldiği üzerinde đurmakta yarar var.

Örgüt kültürü konusundaki değişik bakış açılan nedeniyle ơrgüt kültürünün tanımı farklılık gőstermektedir. Konu ile ilgili yazın incelendiğinde iki ana görüş ile karşılaşıyoruz (Meek, 1988; Smircich, 1983).

Birinci grup kuramcılar kültürü ơrgütün 'sahip olduğu' bir değişken olarak ele alırlar. Bu grup daha tutucu olarak tanımlanabilir. Radikal olarak adlandınlabilecek diǧer grup ise kültürü ơrgütün 'kendisi' olarak ele almayı savunur. Farklllıklar kültür ve örgüt hakkındaki varsayımlardan kaynaklanır. Tutucu kanadın savunduğu kültürün yönetimce yơnlendirilebileceği görüşü yazının bir yanını oluşturur. Bu kuramcılar uygun ve sağlam bir kültürün yaratılmasının örgütsel performansı artırabileceğini savunmuşlardır. Diğer yandan Morgan, Smircich gibi bazı akademisyenler insanların anlamlan pasif olarak özümlemediklerini onlan değiştirdiklerini ileri sürmüşlerdir. Bu yüzden de yönetimin ơrgüt külttürünü bütün olarak yönlendiremeyeceğini savunur, bu da örgüt kültürü yazının diğer kanadının görüşüdür. 
Ơrgüt kültürünün ne olduğu sorulduğunda, bunun toplumsal kültüre benzer şekilde orgütlerde yer alan kültür olduğunu söyleyebiliriz.

Kilmann et al. a göre;

"Örgüt için kültür, birey için kişilik gibi, saklı ama birleştirici, anlam sağlayıcı, yön ve hareket verici bir temadır". (1988:ix)

Toplumsal kültür gibi örgüt kültürü de pek çok soyut şeyden oluşur. Örgüt kültürünün, orgütlerin arkasındaki görünmeyen ve gozlenemeyen bir gụ̧̈ olduğu ve orgütü birarada tutan bir tutkal görevi sürdüğü öne sürülebilir. Hepimizin bildiği gibi orgüt ve yönetim çalışmaları orģüuler için en uygun yapıyı bulmaya odaklanmışur. Etkinlik ve verimliliğe ulaşılması için çeşitli örgüt yapılan denenmiştir. Ancak bunlar orgüt için maddesel bir temel oluşturabilmiştir. Bu da orgütsel başarı için yeterli değildir. Sosyal mckanizmalann örgütsel başan için oynadıklan rol göz ardı edilmemelidir. Örgüt kültürü bu sosyal mekanizmaların toplamıdı̣.

Tutucu olarak değerlendirdiğimiz birinci grup akademisyenler, orgüt kültürünün yönlendirilebileceğine inanmaktadır. Bu akademisyenler örgüt kültürü yazınının ilk donemini oluşturmaktadırlar ancak etkilerinin hala sürdügünü de belirtmemiz gerekmektedir. Bu grubun bir üyesi olan Edgar Schein, ünlü kitabı, Örgüt Kültürü ve Liderlik'de (Organizational Culture and Leadership) kültürü aşağıdaki şekilde tanımlamışur;

"Kültürden kastum: bir grup tarafından, dişsal uyum ve içsel entegrasyon sırasında karşılaşılan problemlerle başetmek için keşfedilen, icad edilen ya da geliştirilen ve doğru olarak kabul edilen ve bundan dolayı yeni üyelerin sorunlarla ilgili algılanı, düşüncelerini ve duygularım bunlara göre düzeltmeleri gereken temel önermelerdir". (aktaran J.M. Shafritz ve J.S. Ou (der.) Classics of Organizational Theory:385)

Bu tanımdan kültürün örgütlerde yönetsel bir özellik olarak bulunduğu ve örgütsel konularda örgüt üyelerinin bütünleşmesini ve kolay hareket etmesini sağladığı anlaşılabilir. Aynı kitapta Schein (1985:1) kültür ve liderlik arasında paralellikler kurmaktadır. Görüşünü, "örgüt kültürleri liderler tarafından oluşturulur.......liderlerin yapukları arasında önemli olan kültürün yaratımı ve yönctimi ve asıl yeteneği kültürle birlikte çalışabilme yetisidir" şcklinde ifade etmektedir.

Bu tanımlarla ilgili olarak. Barley'den bir alınu yapılabilir;

"Metinlerin toplamı olarak hem çalışmaların büyüklüğü hem de kültür teriminin artan popülaritesi, bu konudaki araşurmacılann ve toplumdaki üyelerin, anlık ve anlık olmayan çevrelerini anlamlandırabilmelerine olanak saglayan, toplumsal olarak inşaa edilmiş anlam sistemlerini paylaşan konuşma topluluklan olarak düşünülmesine hazır olduğunu gőstermektedir". (1983:393)

Birinci grupta sayılabilecsk araştırmacılar 'kültür' kavramını yőnetsel bir ozellik olarak kullanmaktadırlar. Örnek olarak Turner (1986), kültüni yönetimin sahip olduğu ve yönlendirmeye açık olan, örgütün ortak bilinci olarak tanımlamaktadır. Bu tür yazarlar kültürün örgütün amaçlarının gerçekleştirilmesi için liderler tarafından kullanıldığı 
görüşünü savunmaktadırlar. Bu yaklaşım çerçevesinde kültür ơrgütsel başan için bir arą̧ rolündedir. Ne zaman yöneticiler 'doğru' veya 'uygun' kültürü brgüt içinde yaratabilirlerse, işte o zaman örgütsel başarı ortaya çıkacaktur demektedirler.

Bazı örgüt kültürü çalışmalarında ise yazarlar vurguyu ơrgüt üyelerine yapmakta ve kültürün ơrgüt içinden doğan bir güç olduğunu sőylemektedirler. Kilmann külttürü, "üyelerinin ortak istekleri" olarak tanımlamakta, bu da "örgütün başa geçmesi, ilerlemesi için gerçekten ne yaptuğı ve ne istedigi" ile ilgilidir (1982). Schwartz ve Davis'e göre "kültür ơrgütteki bireylerin ve grupların davranışlarını biçimlendiren kurallan yaratan örgüt üyeleri tarafindan beniḿsenen inanç ve beklentilerdir" (1981).

Örgüt üyeleri veya örgütün liderleri tarafından yaratılmış olsa da son kertede bu yaklaşım çerçevesinde kültür, başan ve verimlilik için bir araç olarak görülmektedir. Bu yaklaşımla beraber, Kilmann ve arkadaşlarına göre kültür, "kontrol edilebilen bir değişken"dir ve "örgüt kültürlerinin yönetimi artık mümkündür" (1988).

Örgüt kültürü çalışmalarının ikinci gurubunu, kültür kavramına farklı olarak yaklaşan, kültürün bir bütün olarak yönlendirilemeyeceğini savunanlar oluşturmaktadırlar. Kültürün etkileşimsel bir işlem olduğu, bu yüzden de yőnlendirilemeyeceğini söylemcktedirler. Kültür kavramı bu yaklaşımda özellikle kültürel antropolojiden alınmıştur ve nasıl antropologlar, çalışma şckilleri, törenler, hikayeler gibi kültürel öğelerle ilgileniyorlarsa, örgüt kültürü kuramcılan da ơrgütün çalışma şekilleri, tơrenleri ve hikayeleri gibi kültürel öğelerle örgütü incelemektedirler. Bunu yaparken de bu ögeleri listelemenin ötesinde anlamlandırmaya çalışmaktadırlar. Örgüt külttürü yazınında da bu yaklaşım geniş yer bulmuştur (Smircich, 1983; Allaire ve Firsirotu, 1984).

Smircich'e göre;

"Kültür çeşitli önemli fonksiyonlan yerine getiren ve paylaşılan anahtar değer ve inanışlar olarak algılanabilir. tlk olarak örgüt üyelerine bir kimlik duygusu kazandırur. Ikinci olarak, bireyin kendisinden daha büyük bir şeye bağh olmasını sał̆lar. Üçünciu olarak, kültür sosyal sistemin dengesini güçlendirir. Ve dördüncü olarak, davranışlan yönlendiren ve şekillendiren bir rasyonelleştirme servisi olarak işler" (1983:345).

Bu işlevler için kültürün örgütün başarısına yardımcı olduğunu söyleyebiliriz. Kimlik duygusu ve örgütün bir üyesi olma hissi gerçekliği algılamakla ilişkilendirilebilir. Bazı yazarlar da bu konu üzerinde durmuş, örneğin Pettigrew örgüt kültürünün bireyin uyumunu sağladığını ve bülüncül bir kavram olarak ele alınması gerektiğini dile getirmiştir. Kültürü şu şekilde tanımlamıştr;

"Insanların belli bir düzen içinde çalışabilmeleri için devamlı bir gerçeklik duygusuna sahip olmalar gerekir. Kültür belli bir grubun belli bir zamanda işlev görmesi için toplumsal ve kollektif olarak kabul ettiği bir sistemdir" (1979:574).

Hofstede (1980:13), kültürü aynı şckilde tanımlamakta, " bir grup veya kategorideki üye bircylerin bütüncül bir zihni programlanma ile diğerlerinden ayrılması". Bu düşünceye benzer olarak, Beyer (1981:166), ideolojileri, "bazı insanları birbirine 
bağlayan ve bunlara kendi dünyalarını neden ve etkileşim ilişkileri olarak açıklayan, gơreceli olarak tutarlı inanış toplulığu" olarak tanımladı. Trice ve Beyer(1984:654) Beyer ve Pettingew'in tanımlarını birleştirerek, şu hale getirmişlerdir, "herhangi bir sosyal sistemin kültürü paylaşılan ideolojilerin birbirleriyle ilişkilerinden doğar".

Morgan'a göre;

"Kültür hakkında konuşurken aslında insanlann belli olay, hareket, nesne, ifade veya durumu çeşitli şekillerde görme ve anlamasını sał̆layan bir gerçeklik inşaasından konuşuruz. Bu anlayıs şekilleri kişinin davranışlanının mantıklı ve makul olabilmesi için temel sağlar" (1986:128).

'Images of Organization' (Örgütlerin Imajlan) kitabında kültürü, "gerçeklił̌in yaratılmasında sürekli aktif bir işlem" olarak tanımlamıştır. Bu bağlamda gerçekliğin yaraulması sadece yönetimin bir işlevi değil, tüm üyelerin katkıda bulundukları bir süreçtir.

Bu konuda en çok başvurulan yazarlardan biri olan Clifford Geertz, kültürü şoyle tanımlamışur;

"Max Weber gibi, insanın, kendi ordüğ̈̈ belirlilik ağlarında asılı bir hayvan olduğuna inanıyor ve kültürï bu ağlar olarak ele alıyorum, bundan dolayı da bunun analizinin kurallann araştırıldığı deneysel bir bilim olarak değil, anlamın araştınldığı yorumlayıcı bir alan olarak düşünüyorum" (1973:5).

Meek (1988:465), bunu şu şekilde yorumlamıştır, "Kültür insan tarafindan yapılmış belirliliǧin ağlarını olışturuyorsa, yapı da sosyal iletişimin kanalları ve ürünüdür". Pacanowsky ve O'Donnell-Trujillo'nun makalesinde (1990:147), aynı makale alınt olarak kullanılmış ve bu benzetmenin üç özelliği incelenmiştir. Ilk olarak ał̧ metaforu tarışılmıştır. Onlara göre Geertz ağ metaforunu orüınceklerin üzerinde hareket edebileceği tek şey olduğunu göstermek için kullanmıştır ve aynı şckilde kültür de bizim üzerinde hareket ettiğimiz ozel gerçekliği sağlar. Birey bütün kültürel gruplann üyesi olamaz. Ikinci olarak, ağ metaforu iletişim sürecini tanımlamak için kullanılmıştır. Ơrümcek ağı esneyen bir şey olarak tanımlanmıştur. Kişiler kendi ơzgün kültürlerini en disiplinli iş yerinde bile yaratırlar. Onunla dalga geçerler, hastaymıs gibi yaparlar, iletişim kurarlar ve kültürlerini tckrar tekrar yaratırlar. Üçüncü tartı̧̧ma, kültür ve orümcek ağının içerikleri hakkındadır. Bunun için Geertz'in sözlerinin üzerinde durarak, "Kültür bir güç değildir, sosyal olaylar, davranışlar, kuruluşlar veya işlemler birbiriyle ilişkili olarak gelişebilir" (1973:5) demişlerdir. Sonuç olarak, örümcek ağı örümceğin hareketinin sebebi olmadığı gibi, kültür de insan davranışların sebebi değildir.

Burada kültürün yönetim tarafından tümüyle yönlendirilemeyeceğine inanan akademisyenlerin görüşlerine kısaca yer vermeye çalıştık. Yönetim örgüt hayaunda tabii ki bazı etki ve kontrollere sahiptii, ómeğin şirket logosu, veya karar alma yaklaşımları gibi. Fakat pek çok yönden de yönetimin yanı sıra tüm örgüt üyclerinin örgüt kültürünü yaratma, değiştirme ve geliş̧ırme şansları vardır. 
Meek'e göre;

"Eǧer kültür tüm örgüt üyelerinin etkileşiminden oluşuyorsa, yönetimin örgütsel sembolleri, mitleri, adetleri, vb, yönlendirmeye çalışması, yőnetimin sadece bir parçası olduğu tüm örgüt kültürü ile ilişkilendirilmelidir" (1988:463).

\section{Sonus}

Bu farklı yaklaşımlar arasında hangisinin daha geşerli olduğunu sర̋ylemek oldukça güç. Araşturmacılar ơrgüt kültürü konusunda iki yaklaşımı kullanarak da çalışabilirler. Ancak şunu belirtmek gerekir ki, orgütỉ belli bir amaç için bir araya gelmiş bireyler topluluğu olarak tanımlarsak, amacın gerçekleştirilmesi için bireylerin yơnlendirilmesi gereklidir. Örgüt kültürü olgusunu da bu çerçeve içinde dủşünmek gereklidir. Iki yaklaşım arasındaki temel farklılık yönetimin örgüt külltürüyle ilişkisi üzerindedir. Benim konuyla ilişkili yaklaşımım yönetimin örgüt külttürü üzerinde etkili olan en önemli örgütsel ơge olduğu ancak kültürün yapısı gereği bụnun etkileşimsel yơnünün unutulmaması gerektiğidir.

\section{Kaynaklar}

Administrative Science Quarterly, 24(4) Special Issue (1979) Ed. John Van Maanen.

Allaire, Y.\& Firsirotu, M.E.(1984). Theories of Organizational Culture. Organizational Studies, 5/3:193-226.

Barley, S.R. (1983) Semiotics and the study of occupational and organizational cultures. Administrative Science Quarterly, 28(3):393-413.

Beyer, J.M. (1981) Ideologies, values and decision-making in organizations. in P. C. Nystrom and W. H. Starbuck (eds). Handbook of Organizational Design. NY: Oxford University Press.

Business Weck (1980). Corporate culture: The hard to change values that spell success or failure. October 27:148-160.

Fortune Magazine, March, 1982.

Geertz, C. (1973) The Interpretation of Cultures New York: Basic Books.

Hofstede, G., Neuijeu, B., Daval, D. O. and Sanders, G. (1990) Measuring organizational cultures: A qualitative and quantative study across twenty cases. Administrative Science Quarterly, 35:286-316.

Journal of Management (1985) Special Issue: Organizational Symbolism, 11(2). Guest Ed. Frost, P.F.

Lincoln,J.R., Olson,J. and Hanada, M. (1986) Cultural effects on organizational structure: The case of Japanese firms in the United States. American Sociological Review, 43(6): 829-847 
Meek, V.L. (1988). Organizational culture:Origins and Weakness. Organizational Studies, $9 / 4: 453-473$.

Morgan, G. (1986). Images of Organization. Newbury Park, CA:Sage.

Ouchi, W.G. (1981) Theory Z: How American Business Can Meet the Japanese Challange. Reading, MA: Addison-Wesley.

Pacanowsky, M. E. and O'Donnell-Trujillo, N. (1990). 'Communication and Organizational Cultures'. pp:142-153 in Corman et al. (eds). Foundations of Organizational Communication: A Reader. NY:Longman press.

Pass, C., Lowes, B., Pendleton, A. and Chadwick, L. (1991). Collins Dictionary of Business. Glasgow:Harper Collins Publishers.

Pettigrew, A.M.(1979). On Studying, Organizational Cultures. Administrarive Science Quarterly, 24:570-580.

Peters, T. J. and Waterman, R. H. (1982). In Search of Excellence. NY: Harper \& Row.

Schein, E.H. (1985). Organizational Psychology. Englewood Cliffs, NJ: Prentice-Hall.

Schwartz, H.\& Davis, S. (1981). Matching Corporate Culturc to Business Strategy. Organizational Dynamics, Summer:30-48.

Shafritz, J.M. \& Ott, J.S. (Eds.).(1987). Classics of Organization Theory. Illinois, Chicago: The Dorsey Press.

Smircich, L. and Calas, M. B. (1987). 'Organizational culture: A critical assesment' pp: 195-227 in Jablin et al. (eds) Handbook of organizational communication. NY: Sage Publications.

Smircich, L. (1983). Organizational Culture and Organizational Analysis. Administrative Science Quarterly,28:339-358.

Trice, H. M., Belasco, J. Alutto, J. (1969) The role of ceremonials in organizational behavior. Industrial and Labor Relations Review, 23(October): 40-51.

Trujillo, N. (1985). Organizational communication as cultural performance. Southem Speech Communication Journal, 50:210-244.

Turner, B. A. (1986). Sociological aspects of organizational symbolism. Organizational Studies, 7(2): 101-115.

Wilkins, A.L. \& Ouchi, W.G. (1983). Efficient cultures: Exploring the relationship between culture and organizational performance. Administrative Science Quarterly, 28:468-481. 